\title{
A THEOREM OF LEVITZKI
}

\section{N. HERSTEIN}

Levitzki [2] proved that in a ring satisfying the ascending chain condition on left-ideals every left-ideal consisting of nilpotent elements is nilpotent. More recently, Goldie [1] has given a simpler proof. We present here a proof which is, in our opinion, even simpler and more elementary than that of Goldie. Moreover, it is completely self-contained.

TheOREM (LeVITZKI). In a ring with ascending chain condition on left-ideals a nil left-ideal must be nilpotent.

Proof. We claim that we may assume that the ring $R$ has no nonzero nilpotent left-ideals, for if it did, it would have a nonzero nilpotent two-sided ideal, hence a maximal such, $N$. If the result were false, in $R / N$, which has no nilpotent left-ideals we would have a nonzero nil left-ideal.

So suppose that $R$ is a ring with ascending chain condition on leftideals which has no nonzero nilpotent left-ideals and that $A \neq(0)$ is a nil left-ideal of $R$. Let $a \neq 0 \in A$, and let $\mathfrak{N}=\{a x \neq 0 \mid x \in R\}$. For $a x \in \mathfrak{N}$ let $L(a x)=\{y \in R \mid y a x=0\}$; these give us a set of left-ideals of $R$, which, by the ascending chain condition has maximal elements. We denote these maximal elements by $L\left(a x_{i}\right)$.

If $t \in R$ and $a x_{i} t \neq 0$ then $L\left(a x_{i} t\right) \supset L\left(a x_{i}\right)$ which, together with $a x_{i} t \in \mathscr{T}$ forces $L\left(a x_{i} t\right)=L\left(a x_{i}\right)$. We claim that given any finite number of such maximal $a x_{i},-a x_{1}, \cdots, a x_{n}$-then there is an element $u \neq 0$ in $\operatorname{Rax}_{1} R$ such that $a x_{1} u=\cdots=a x_{n} u=0$. Suppose such a $u$ has been found such that $a x_{1} u=\cdots=a x_{n-1} u=0$. If $a x_{n} u=0$ then we are done. So suppose any $u \neq 0 \in \operatorname{Rax}_{i} R$ annihilating $a x_{1}, \cdots$, $a x_{n-1}$ does not annihilate $a x_{n}$. We claim there is such a $u \neq 0$ such that $u a x_{n} \neq 0$; for if $u a x_{n}=0$ for all $u \in \operatorname{Rax}_{1} R$ which annihilate $a x_{1}, \cdots$, $a x_{n-1}$, then since $u R$ also does the trick, $u \operatorname{Rax} x_{n}=(0)$, whence $\left(\operatorname{Rax}_{n} u\right)^{2}$ $=(0)$. But then $\operatorname{Rax}_{n} u$ is a nilpotent left-ideal, so must be (0). This forces $a x_{n} u=0$ the desired result. Thus we may suppose that $u a x_{n} \neq 0$. Now $\left(u a x_{n}\right)^{t}=0$ for some $t$, since $x_{n} u a \in A$ is nilpotent. If $\left(u a x_{n}\right)^{t}=0$, $\left(u a x_{n}\right)^{t-1} \neq 0$, then $u a x_{n}\left(u a x_{n}\right)^{t-1}=0$. Since $u \in L\left(\operatorname{ax}_{n}\left(u a x_{n}\right)^{t-1}\right)$ but $u \notin L\left(a x_{n}\right)$, by the remark at the beginning of this paragraph, $a x_{n}\left(u a x_{n}\right)^{t-1}=0$. Thus $\left(u a x_{n}\right)^{t-1} \neq 0$ annihilates $a x_{1}, \cdots, a x_{n-1}$ and $a x_{n}$; moreover since $u \in \operatorname{Rax}_{1} R,\left(u a x_{n}\right)^{t-1}$ also is.

Consider the ascending chain of left-ideals $\operatorname{Rax}_{1}, \operatorname{Rax}_{1}+\operatorname{Rax}_{2}, \cdots$,

Received by the editors February 27, 1961. 
$\operatorname{Rax}_{1}+\operatorname{Rax}_{2}+\cdots+\operatorname{Rax}_{n}, \cdots$. It must terminate; thus for some $n$, $\operatorname{Rax}_{i} \subset \operatorname{Rax}_{1}+\cdots+\operatorname{Rax}_{n}$ for all $a x_{i}$ such that $L\left(a x_{i}\right)$ is maximal. Now $a x_{1} r$ is either 0 or a maximal $a x_{i}$; whence $\operatorname{Rax}_{1} R \subset \operatorname{Rax}_{1}+\ldots$ $+\operatorname{Rax}_{n}$. But there is a $u \neq 0$ in $\operatorname{Rax}_{1} R$ such that $a x_{1} u=\cdots=a x_{n} u$ $=0$. Thus $\operatorname{Rax}_{1} R u \subset \operatorname{Rax}_{1} u+\cdots+\operatorname{Rax}_{n} u=(0)$. Therefore, since $R u \neq 0 \subset \operatorname{Rax}_{1} R,(R u)^{2} \subset \operatorname{Rax}_{1} R R u=(0)$. We have produced a nonzero nilpotent left-ideal in $R$ !. This contradiction proves the theorem.

Clearly the proof would work if $A$ were a nil right-ideal, for if $0 \neq a \in A$, then $R a$ would be a nonzero nil left-ideal of $R$.

\section{REFERENCES}

1. A. W. Goldie, Semi-prime rings with maximum condition, Proc. London Math. Soc. 10 (1960), 201-220.

2. Nathan Jacobson, The structure of rings, Amer. Math. Soc. Colloq. Publ. Vol. 37, Amer. Math. Soc., Providence, R. I., 1956.

\section{CORNELl UNIVERSITY AND \\ The University of Chicago}

\section{A REMARK ON DIRECT PRODUCTS OF MODULES}

\section{STEPHEN U. CHASE}

It is a standard result of abelian group theory that the direct product of an infinite number of infinite cyclic groups is not free [3, p. 48]. Various generalizations of this fact to modules over an arbitrary ring are contained in [1]. In this note we restrict our attention to integral domains, and in this setting present a generalization of the aforementioned result which is similar to, but in some sense stronger than, those of [1]. We then apply our theorem to show that any factor group $A$ of a direct product of infinite cyclic groups possesses the following amusing property: If $A$ is a subgroup of a direct sum of reduced torsion-free abelian groups, then it must be contained in the direct sum of a finite number of them.

Throughout this discussion, $R$ will be an integral domain which is not a field. All $R$-modules considered will be assumed to be unitary.

Lemma. Let $A$ be a torsion-free $R$-module, and set $A^{\prime}=\bigcap_{\lambda \in R^{*}} \lambda A$. Then $A^{\prime}$. is divisible. In particular, if $A$ is reduced (i.e., has no divisible submodules) then $\bigcap_{\lambda \in R^{*}} \lambda A=0 .^{1}$

Received by the editors February 24, 1961

${ }^{1} R^{*}$ means $R-\{0\}$. 